\title{
Message of the President of the Brazilian League of Epilepsy
}

$\mathrm{O}$

XXXII CONGRESSO DA LIGA BRASILEIRA DE EPILEPSIA será realizado entre os dias 12 e 15 de junho de 2007 no Hotel Royal Palm Plaza em Campinas, SP.

Este congresso é um dos mais tradicionais eventos científicos da comunidade médica brasileira. Acontece de forma regular a cada dois anos e conta com a parceria da Sociedade Brasileira de Neurofisiologia Clínica que realiza sua reunião anual junto ao congresso da LBE. Nos anos ímpares, a LBE realiza sua reunião anual junto ao Congresso Brasileiro de Neurofisiologia Clínica.

A LBE foi fundada em 15 de agosto de 1949 por Paulo Niemeyer, na Santa Casa de Misericórdia do Rio de Janeiro. Desde então é filiada a International League Against Epilepsy - ILAE. A LBE é uma sociedade sem fins lucrativos que conta como associados neurocientistas, profissionais médicos e de outras áreas da saúde que trabalham para o avanço no conhecimento científico com objetivo final de melhorar o tratamento e a qualidade de vida das pessoas com epilepsia.

O Congresso da Liga Brasileira de Epilepsia é a reunião científica mais importante do país na área de epileptologia. O XXXII CONGRESSO DA LIGA BRASILEIRA DE EPILEPSIA abordará aspectos recentes da pesquisa básica (experimental), pesquisa clínica aplicada, e avanços científicos nas diversas áreas relacionadas ao estudo das epilepsias. Dentre os diversos temas a serem abordados no programa científico incluem: Epileptogênese e outros aspectos da investigação experimental em epilepsia; estudos de biologia molecular e genética molecular e mecanismos de ação e resistência aos fármacos antiepilépticos; avanços em neuroimagem e suas contribuições para a compreensão da biologia, diagnóstico e tratamento cirúrgico; avanços em eletrofisiologia e fármacoterapia. Além disso, este congresso dará ênfase especial para atualização médica sobre os aspectos clínicos, diagnóstico e tratamento das comorbidades psiquiátricas em epilepsia.

A qualidade científica deste encontro será de alto nível, como sempre acontece nos eventos da LBE. Serão abordados cerca de 200 trabalhos científicos na forma de pôsteres e plataforma após seleção criteriosa pela comissão científica. A data limite para o envio de resumos será 25 de fevereiro de 2007 (consulte o site do congresso: www.eventus.com.br/epilepsia).

Contamos com a presença de todos colegas neste evento.

Aproveito para desejar a todos Boas Festas e um Próspero Ano Novo!

\author{
Fernando Cendes \\ Presidente da Liga Brasileira de Epilepsia \\ 2006-2008
}

